\title{
Smart meters persist
}

Futures http://doi.org/cs65 (2018)

The policy process culminating in the UK Smart Meters Implementation Programme was long, from initial review in 2001 to rollout in 2016. Indeed, it is remarkable that smart meters maintained their position in energy policy given the political changes that occurred over this period. Sabine Hielscher and Paula Kivimaa from the University of Sussex, with secondary affiliations at Technische Universität Berlin and the Finnish Environment Institute, respectively, examined how the discourse of smart meters in UK energy policy evolved in relation to shifts in policy context.

The researchers conducted content and thematic analyses of UK energy policy documents that mention smart meters from 2000 to 2016 . They found that early mentions of smart meters focused on their potential to enable emissions reductions, consistent with government emphasis on environmental goals at the time. However, when energy security emerged on the policy agenda in 2007 , smart meters were positioned as a means to enable off-peak energy use to promote security of energy supply. More recently, smart meters have been described as empowering consumers and enabling a smart grid, which mirrors investments into UK energy infrastructure aimed at creating a smart and responsive electricity system. Thus, expectations about what smart meters will be able to achieve has been adjusted over time to match changes in energy policy objectives, allowing smart meters to remain a relevant policy instrument and legitimizing their implementation, despite limited evidence that they can actually live up to these ambitions.

Jenn Richler

Published online: 10 September 2018

https://doi.org/10.1038/s41560-018-0252-7 